\title{
Perceptual organization influences visual working memory
}

\author{
GEOFFREY F. WOODMAN, SHAUN P. VECERA, and STEVEN J. LUCK \\ University of Iowa, Iowa City, Iowa
}

\begin{abstract}
Previous studies have demonstrated that top-down factors can bias the storage of information in visual working memory. However, relatively little is known about the role that bottom-up stimulus characteristics play in visual working memory storage. In the present study, subjects performed a change detection task in which the to-be-remembered objects were organized in accordance with Gestalt grouping principles. When an attention-capturing cue was presented at the location of one object, other objects that were perceptually grouped with the cued object were more likely to be stored in working memory than were objects that were not grouped with the cued object. Thus, objects that are grouped together tend to be stored together, indicating that bottom-up perceptual organization influences the storage of information in visual working memory.
\end{abstract}

Over the past 50 years, immediate memory storage has been a topic of much interest among cognitive psychologists (Averbach \& Coriel, 1961; Brown, 1958; Peterson \& Peterson, 1959; Phillips, Shiffrin, \& Atkinson, 1967; Sperling, 1960). Although early studies used the unitary term short-term memory to characterize this type of memory storage, Baddeley and colleagues have proposed that immediate memory storage is better described as a multiple-component working memory system (Baddeley, 1986; Baddeley \& Hitch, 1974). This system consists of a central executive and several modality-specific slave stores. The slave store for verbal information was initially the focus of most research, but visual working memory has received increasing scrutiny in recent years (see, e.g., Carlson-Radvansky \& Irwin, 1995; Cowan, 1998; Dell' Acqua \& Jolicœur, 2000; Irwin \& Andrews, 1996; Jiang, Olson, \& Chun, 2000; Lee \& Chun, 2001; Logie, 1995; J. Palmer, 1988; Pashler, 1988; Potter, 1976; Simons, 1996; Vogel, Woodman, \& Luck, 2001; Walker \& Cuthbert, 1998).

Previous studies of visual working memory have indicated that almost all real-world scenes provide the visual system with more information than can be represented in this capacity-limited memory store. In change blindness experiments, for example, an observer views two alternating versions of a photograph that differ in the presence or absence of one object in the scene. Even if the

This study was supported by a National Research Service Award from the National Institutes of Health (1 F31 MH12995-01) and by grants from the National Institute of Mental Health (MH56877 and MH60636), the National Science Foundation (SBR 98-09126 and BCS 99-10727), and the Human Frontier Science Program (RG0136). We thank Nelson Cowan and two anonymous reviewers for valuable suggestions. Correspondence should be addressed to G. F. Woodman, Department of Psychology, University of Iowa, 11 Seashore Hall E, Iowa City, IA 52242-1407 (e-mail: geoff-woodman@uiowa.edu). object is large, it may take dozens of alternations for an observer to detect the change (see the review by Simons \& Levin, 1997). Studies with simpler stimuli have shown that observers can remember only three to four objects from a given display (Vogel et al., 2001).

When faced with an above-capacity array of objects, how does the visual system select which subset of objects to store in its limited memory space? Empirical evidence supports the existence of both bottom-up and top-down mechanisms for biasing the input to visual working memory. Evidence for top-down control over the storage of information in visual working memory comes from the classic iconic memory experiments of Sperling (1960). In these experiments, three rows of letters and digits were presented, followed by a tone that indicated which row of characters should be reported. Subjects were able to selectively transfer representations from the cued row into working memory (see also Averbach \& Coriel, 1961; J. Palmer, 1990).

Change blindness studies also suggest that top-down inputs from long-term memory influence the transfer of information into visual working memory. Specifically, Rensink, O'Regan, and Clark (1997) proposed that changes are most likely to be detected in regions of central interestthat is, locations in the picture that are most relevant for scene recognition. Presumably, knowledge of the structure of visual scenes is used to direct attention to regions of interest and, thus, influences the storage of information in visual working memory.

Although it is clear that top-down factors may influence the transfer of information into working memory, there is little evidence indicating that bottom-up information from the visual input also impacts memory storage. One study has shown that exogenous spatial precues can influence the entry of information into visual working memory in a bottom-up manner (Schmidt, Vogel, Woodman, \& Luck, 2002). In that study, objects pre- 


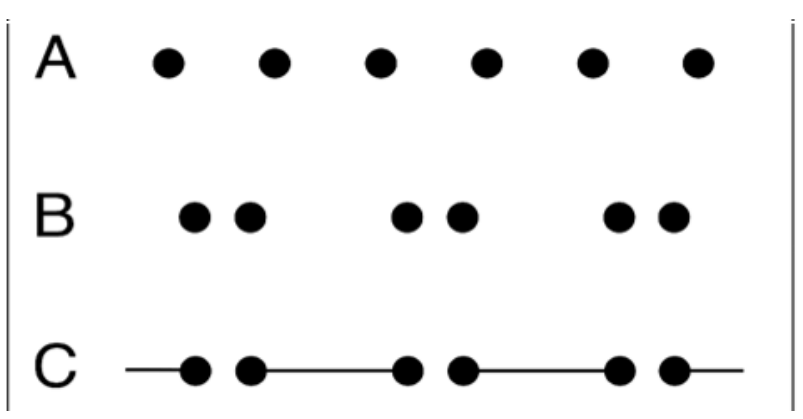

Figure 1. Examples of displays that have (A) no strong grouping of elements, (B) elements grouped by their proximity, and (C) elements grouped by connectedness. Adapted from S. E. Palmer and Rock, 1994b; copyright Psychonomic Society, Inc., 1994.

ceded by a brief task-irrelevant peripheral flash of light were more likely to be remembered than objects that were not cued in this manner. To our knowledge, this is the only study that has explicitly examined bottom-up influences on visual working memory storage. In the present experiments, we further explored the role of bottom-up factors in visual working memory storage. Specifically, we tested the hypothesis that bottom-up perceptual grouping cues may bias the entry of items into visual working memory.

Although many grouping cues have been proposed, we focused on proximity (Wertheimer, 1924/1950) and connectedness (S. E. Palmer \& Rock, 1994b). Proximity, the first Gestalt grouping principle proposed by Wertheimer (1924/1950), states that nearby objects are more likely to be grouped together than are distant objects. Panels A and $\mathrm{B}$ of Figure 1 illustrate grouping by proximity. More recently, S. E. Palmer and Rock (1994b) have proposed the principle of element connectedness. This principle proposes that elements that are connected together tend to be grouped together. Figure $1 \mathrm{C}$ illustrates how connectedness can overpower proximity, joining together relatively distant elements into perceptual groups.

Perceptual grouping processes are thought to occur at a preattentive stage of the visual-processing hierarchy (Neisser, 1967; Treisman, 1988), and these processes provide the inputs to later processing stages (e.g., object recognition or visual attention; see S. E. Palmer \& Rock, 1994a; Vecera, Behrmann, \& McGoldrick, 2000; Vecera \& O'Reilly, 1998). We hypothesized that grouping principles also influence what elements are stored in visual working memory. Specifically, we predicted that when one element of a group is stored in working memory, other elements of the same group are likely to be stored as well. In short, items that are grouped together are stored together.

In three experiments, we tested the ability of Gestalt cues to influence which objects are stored in visual working memory. Although previous studies have reported that the general configuration of information can influence visual working memory storage (Jiang et al., 2000; Rensink et al., 1997), our study explicitly addressed whether bottom-up cues that influence perception also influence working memory.

In our experiments, we used a spatial precuing paradigm similar to that developed by Egly, Driver, and Rafal (1994) to study object-based attention. Our experiments, however, focused on the entry of items into visual working memory. In these experiments, a peripheral cue was used to attract attention to one of several to-be-remembered objects. Some of the to-be-remembered objects were grouped by proximity or connectedness to the cued object, and we predicted that these objects would be remembered better than objects that were not grouped with the cued object.

\section{EXPERIMENT 1}

In Experiment 1, we examined whether the Gestalt grouping cue of proximity influences storage in visual working memory. Subjects viewed four or six colored squares in arrays such as those shown in Figure 2A. Two arrays were presented: a sample array, followed after a short delay by a test array. The task was to indicate whether these arrays were identical or differed in the color of one item. Each trial began with the presentation of a spatial precue that consisted of a white dot at one of four possible locations on the monitor. The cued location was at the center of one of the colored squares in the sample array. The precue was used to bias the allocation of attention to the cued location in the subsequently presented sample array (Posner, 1980; Schmidt et al., 2002). The precue was uninformative about the location of the color change, however, and the subjects were encouraged to remember all of the colored squares equally well. We relied on the exogenous attention-capturing ability of the luminance increment to attract attention.

When the memory array consisted of four squares, the squares were presented equidistant from each other (Locations 1, 3, 4, and 6 in Figure 2A). This configuration did not bias any particular grouping of the squares. When six squares were presented, the two additional squares were presented in Locations 2 and 5, biasing the subjects to form vertically oriented groups based on proximity (these arrays were rotated by $90^{\circ}$ on half of the trials, to form horizontal groups). These two additional squares were used solely to bias the grouping of the other squares, and they never changed color between the sample and the test arrays.

If Gestalt cues bias the transfer of information into working memory, the cue should increase the probability that other members of that group are stored in working memory. For example, when the six items are grouped to form vertical columns, cuing Location 1 should result in better memory of the color at Location 3 than of the color at Location 4, even though these items are equidistant from the cued location. In contrast, when the items are presented without grouping cues (i.e., arrays of four items), there should be no advantage for Location 3 over Location 4. 

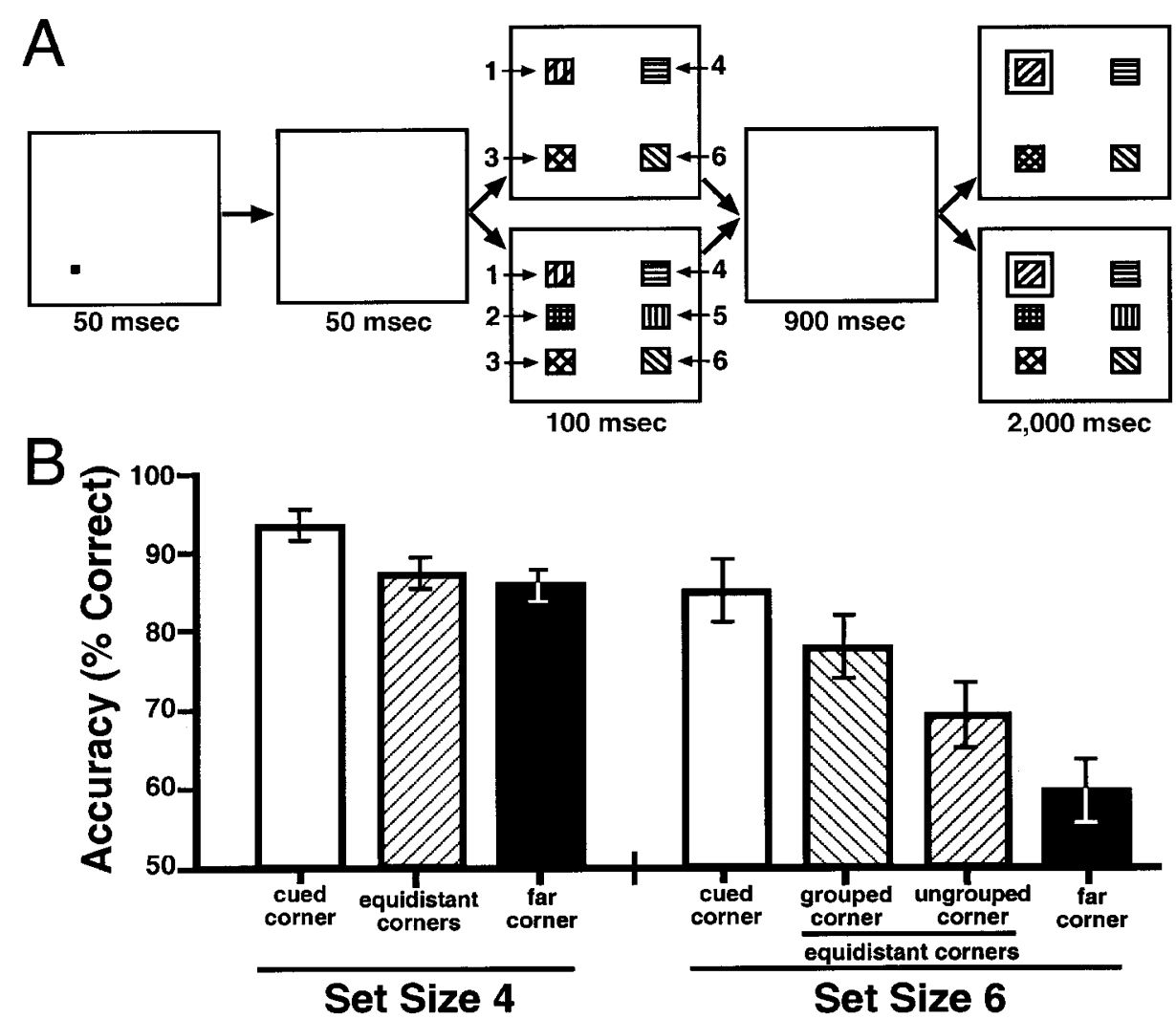

Figure 2. (A) Illustration of the stimulus sequence used in Experiment 1. The numbers and arrows in the sample arrays are shown to assist in describing the locations and were not seen by the subjects. Half of the set size 6 stimuli were presented as two horizontal rows (not shown). (B) Change detection accuracy from Experiment 1; left, data from set size 4; right, data from set size 6. Error bars represent $95 \%$ within-subjects confidence intervals, as described by Loftus and Masson (1994).

Two other aspects of the procedure require comment. First, a decision box appeared around one of the items in the test array, and the subjects were told that this was the one item that might have changed color and that they should base their responses on their memory for that item. This made it possible to isolate the memory at specific locations. Second, the subjects performed an articulatory suppression task while performing this experiment in order to minimize the transfer of information from the sample arrays into verbal working memory. The subjects repeated a string of digits aloud at a rate of three to four digits per second, which significantly impairs verbal recoding of visual stimuli (Baddeley, 1986; Besner, Davies, \& Daniels, 1981).

\section{Method}

Subjects. Twelve students from the University of Iowa, with normal or corrected-to-normal vision, participated for class credit.

Stimuli. The stimuli were presented on a video monitor with a gray background $\left(0.62 \mathrm{~cd} / \mathrm{m}^{2}\right)$ at a viewing distance of $70 \mathrm{~cm}$. Arrays were composed of individual colored squares that subtended $0.65^{\circ} \times 0.65^{\circ}$ of visual angle. The color of each square was selected at random (with one replacement) from a set of seven highly dis- criminable colors (for specific color coordinates, see Vogel et al., 2001). When a square changed color between the sample and the test arrays, the new color value was selected at random from the remaining colors. The spatial precue was a white $\left(65.38 \mathrm{~cd} / \mathrm{m}^{2}\right)$ dot that subtended $0.1^{\circ} \times 0.1^{\circ}$ and was centered on the future location of an item in the sample array. The decision box was an outlined square $\left(0.97^{\circ} \times 0.97^{\circ}\right.$, line thickness of $\left.0.03^{\circ}\right)$ drawn in light brown.

Memory arrays contained either four or six colored squares. When four colored squares appeared, each colored square was centered on the corner of a large imaginary square $\left(3.58^{\circ} \times 3.58^{\circ}\right)$ centered on the middle of the monitor. The corners of this imaginary square correspond to Locations 1, 3, 4, and 6 in Figure 2A. Sample arrays with six items contained squares at these same four locations, along with one square halfway between Locations 1 and 3 and another square halfway between Locations 4 and 6 . On half of the trials, the arrays were rotated $90^{\circ}$ such that the six-item arrays formed two rows instead of two columns.

Procedure. Each trial began with a 500-msec presentation of two digits that the subjects were required to repeat aloud throughout the trial to inhibit verbal recoding of the stimuli. After a 1,000-msec blank interval, a white dot was presented for $50 \mathrm{msec}$ at one of the four corner locations (Location 1, 3, 4, or 6). After a 50-msec blank interval, the sample array was presented for $100 \mathrm{msec}$. The sample array was followed by a 900-msec blank retention interval and then by a 2,000-msec presentation of the test array. The sample and the test arrays were identical on 50\% of the trials and differed in the 
color of one item on the remaining trials. A decision box was always present in the test array, and when a color changed, it was always in the location marked by the decision box. The decision box appeared equiprobably at the four corner locations (1, 3, 4, and 6) and was uncorrelated with the location of the precue. That is, the decision box appeared at the cued location on $25 \%$ of the trials and at a randomly selected uncued location on the remaining trials. The subjects were encouraged to remember all of the colored squares.

In this design, the decision box could appear (1) at the cued location (henceforth called the cued corner), (2) at one of the two uncued locations that were equidistant from the cued location (the equidistant corners), or (3) at the uncued location at the opposite corner of the display from the cued location (the far corner). For sample arrays with six items, the equidistant corners can be further subdivided into the corner that is grouped with the cued corner (the grouped uncued corner) and the equidistant corner that is not in the cued group (the ungrouped uncued corner). Only the data from the cued corner and the equidistant corners were relevant for the present hypotheses, so although the data from the far corner will be shown, they were excluded from the statistical analyses.

The subjects made unspeeded, two-alternative forced-choice responses on a response pad at the end of each trial. Once they responded, the subjects were allowed to stop articulating the digits. The next trial began after an intertrial interval of 1 sec. Each subject received three blocks of 128 trials, yielding a total of 24 trials for each combination of cued location, decision box location, set size, and change status of the tested item. All of these variables varied unpredictably within blocks.

\section{Results and Discussion}

Accuracy for both change and no-change trials was computed across the 4 possible decision box locations. ${ }^{1}$ The results are summarized in Figure 2B. At set size 4, change detection accuracy was greater at the cued corner $(M=93 \%)$ than at the equidistant uncued corners $(M=$ $87 \%)$ or the far corner $(M=86 \%)$. At set size 6 , accuracy was again greatest at the cued corner $(M=85 \%)$. More important, accuracy was substantially greater at the grouped uncued corner $(M=81 \%)$ than at the equidistant ungrouped uncued corner $(M=69 \%)$. These results show evidence of two separate phenomena: a spatial effect (reflected in greater accuracy at the cued location than at any of the uncued locations) and a grouping effect (reflected in greater accuracy at the grouped uncued corner than at the ungrouped uncued corner).

These observations were supported statistically by separate analyses of variance (ANOVAs) for the set size 4 and set size 6 trials. At set size 4, performance at the cued corner was compared with the average of the equidistant uncued corners, and the difference in accuracy between these conditions was significant $[F(1,11)=$ $18.33, p<.01]$. At set size 6 , a one-way ANOVA was performed, with three levels: cued corner, grouped uncued corner, and ungrouped uncued corner. These conditions were significantly different from each other $[F(2,22)=9.49, p<.01]$. Planned comparisons showed that accuracy was significantly greater at the cued corner than at the grouped uncued corner $[F(1,11)=6.79, p<$ .03 ] and was also significantly greater at the grouped uncued corner than at the ungrouped uncued corner $[F(1,11)=15.73, p<.01]$.
These results support the hypothesis that grouping cues influence how information is stored in visual working memory. In our next experiment, we sought converging evidence for this hypothesis by demonstrating that another grouping cue-connectedness-also biases visual working memory storage.

\section{EXPERIMENT 2}

In Experiment 2, we pitted the cue of connectedness against the cue of proximity, using stimuli similar to those used in Experiment 1. The sample and the test arrays used in Experiment 2, depicted in Figure 3A, were the same as those used in Experiment 1, except that opposite pairs of the colored squares were connected by two lines. These connectedness cues grouped items horizontally, whereas the proximity cues grouped items vertically (or vice versa when the stimuli were rotated by $90^{\circ}$ ). S. E. Palmer and Rock (1994b) showed that connectedness cues can override the perceptual organization provided by proximity cues (see Figure 1). We predicted that if connectedness cues can override the grouping of elements for visual working memory storage, as they do during perceptual organization, then subjects should be more accurate at detecting changes in the uncued item that is connected to the cued item than at detecting changes in the uncued items that are not connected to the cued item. The use of the connectedness grouping cue also allowed us to examine the effect of the grouping cue across different set sizes, because, unlike in Experiment 1, the set size 4 arrays contained grouping via connectedness.

\section{Method}

The method was identical to that in Experiment 1, except as follows. A new set of 12 subjects from the same pool participated. Two gray lines $\left(37.45 \mathrm{~cd} / \mathrm{m}^{2}\right)$ connected the corners of the opposing pairs of colored squares in each of the arrays. When the sample array contained four items, horizontal lines were used to form horizontal groups on half of the trials (as is illustrated in Figure 3A), and vertical lines were used to form vertical groups on the other half. When the sample array contained six items, horizontal lines were used to form horizontal groups if the proximity cues formed vertical groups (as is illustrated in Figure 3A), and vertical lines were used to form vertical groups if the proximity cues formed horizontal groups. We will use the term connected uncued corner to refer to the uncued location that was connected by the lines to the cued corner and the term unconnected uncued corner to refer to the equidistant uncued location that was not connected by the lines to the cued corner.

\section{Results and Discussion}

Figure 3B shows the mean accuracy for each condition in Experiment 2. When four items were presented, the subjects were best at detecting changes in the cued item $(M=93 \%)$ and were similarly good at detecting changes in any of the uncued items (connected uncued corner, $M=91 \%$; unconnected uncued corner, $M=91 \%$; far corner, $M=90 \%$ ). However, these differences were smaller than those in Experiment 1, and they did not 

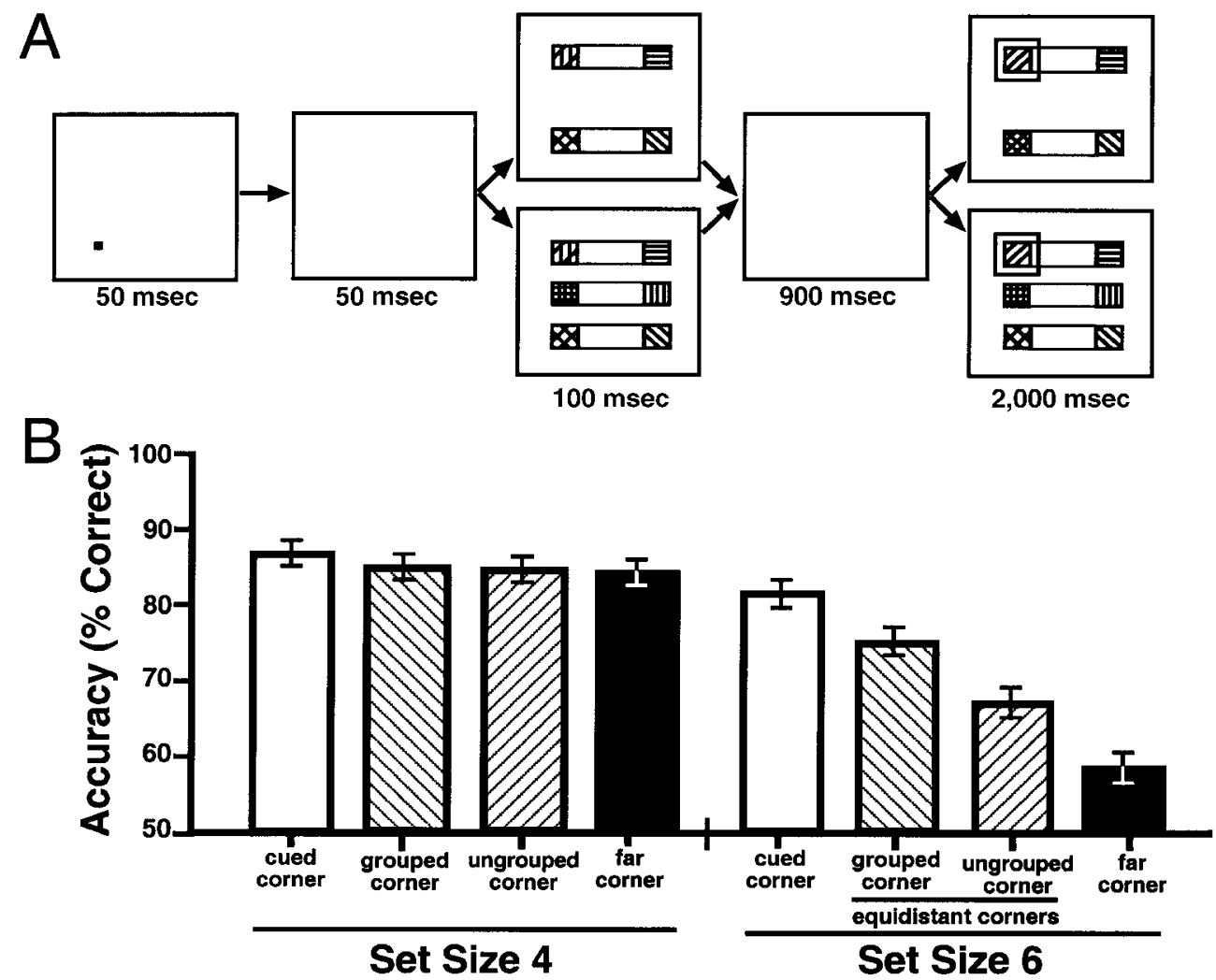

Figure 3. (A) Illustration of the stimuli presented in Experiment 2. Half of the stimuli were presented as two horizontal rows with vertical connectors (not shown). (B) Change detection accuracy from Experiment 2; left, data from set size 4 stimuli; right, data from set size 6 stimuli. Error bars represent withinsubjects $95 \%$ confidence intervals.

reach statistical significance in a one-way ANOVA that compared the cued corner, the connected uncued corner, and the unconnected uncued corner $(p>.30)$. Thus, grouping had a negligible effect for arrays that were within (or nearly within) the storage capacity of visual working memory. This may indicate that bottom-up biases have little effect on storage unless working memory is significantly overloaded.

When six items were presented, accuracy was highest at the cued corner $(M=89 \%)$, slightly lower at the connected uncued corner $(M=83 \%)$, and lower still when the unconnected items were tested (unconnected uncued corner, $M=77 \%$; far corner, $M=64 \%$ ). This pattern of effects was significant in a one-way ANOVA comparing the cued corner, the connected uncued corner, and the unconnected uncued corner $[F(2,22)=25.39, p<.001]$. Planned comparisons indicated that accuracy was greater at the cued corner than at the connected uncued corner $[F(1,11)=8.01, p<.05]$ and that accuracy was greater at the connected uncued corner than at the unconnected uncued corner $[F(1,11)=20.77, p<.001]$. Thus, for arrays that exceeded the storage capacity of working memory, connectedness was able to override the proximity effect observed in the previous experiment, biasing the subjects to store objects grouped via connectedness to the cued location.

The results of this experiment provide further support for the proposal that perceptual grouping influences storage in visual working memory. In addition, these results expand the basic conclusion that Gestalt cues can influence visual working memory storage, because they suggest that the influence of some grouping cues can be overridden by other cues when the two cues provide conflicting grouping information.

\section{EXPERIMENT 3}

It is possible that the Gestalt grouping effects observed in Experiments 1 and 2 were caused by the spreading of perceptual-level attention within the cued group, and not by working memory processes per se. For example, it is possible that all of the items in the sample arrays were transferred into visual working memory with the same priority but that the items in the cued group were perceived more accurately and were, therefore, stored with greater fidelity in working memory. In this 
manner, object-based effects on perceptual processing could be masquerading as object-based effects on working memory storage.

It is unlikely that attention had a substantial influence on perception in Experiments 1 and 2, because the stimuli were highly discriminable color patches that should have produced high-fidelity perceptual representations even without focused attention. However, to rule out this possibility, an additional experiment was conducted. To demonstrate that the grouping effects reflected differential transfer into working memory, rather than differential perception, we used a variant of Sperling's (1960) postcue procedure to isolate the transfer of postperceptual representations into working memory (see also Schmidt et al., 2002). Specifically, we used the procedure of Experiment 1, but we included a condition in which the cue followed the sample array, rather than preceding it. When the cue is presented after the offset of the sample array, there should be little or no opportunity for attention to modulate the perceptual processing of the sample array, because perceptual input is no longer available. Indeed, many studies of the effects of spatial cues on perception have shown that cues are effective only when they precede the target stimuli (Eriksen \& Hoffman, 1972; Luck, Hillyard, Mouloua, \& Hawkins, 1996; Lyon, 1990; Nakayama \& Mackeben, 1989). However, as in Sperling's classic iconic memory experiments, it should be possible for a postcue to influence the transfer of iconic memory representations into working memory. Thus, if the grouping effects that we observed in Experiment 1 are just as large with a postcue as with a precue, they cannot be a mere side effect of the allocation of perceptual-level attention to the cued group.

\section{Method}

The method was identical to that in Experiment 1, except as follows. A new group of 12 subjects participated. The stimulus arrays always contained six items. In the precue condition, the cue appeared before the sample array, and in the postcue condition, the cue appeared after the sample array. To avoid backward masking of the sample array by the cue, we used an outlined box centered around the cued item as the cue. This cue was the same size and color as the decision box used in Experiment 1. The decision box was therefore replaced with a brown bar $\left(0.15^{\circ} \times 0.10^{\circ}\right)$ that was centered $0.65^{\circ}$ lateral to the center of one of the corner items.

In the precue condition, the cue was presented with the same temporal parameters as those in Experiment 1 (i.e., 50-msec duration, 100-msec stimulus onset asynchrony). In the postcue condition, the cue was presented for a duration of $50 \mathrm{msec}$, beginning $50 \mathrm{msec}$ after the offset of the sample array. Precue and postcue trials were randomly interleaved within the three blocks of 128 trials each.

\section{Results and Discussion}

Figure 4 shows the results from the precue and postcue conditions. Cue validity effects were observed in both conditions, as were grouping effects. That is, accuracy was greater at the grouped uncued corner than at the ungrouped uncued corner in both the precue and the postcue conditions. Indeed, this effect was somewhat larger in the postcue condition than in the precue condition.

Grouping effects were examined in a two-way ANOVA with factors of cue type (precue vs. postcue) and location (grouped uncued corner vs. ungrouped uncued corner). This ANOVA yielded a significant main effect of location $[F(1,11)=6.05, p<.05]$, reflecting the greater accuracy observed at the grouped uncued corner than at the ungrouped uncued corner. Accuracy at both locations was somewhat greater in the precue condition than in the postcue condition $[F(1,11)=10.52, p<.01]$. Although the difference between the grouped and the ungrouped locations was greater for postcue trials than for precue trials, location did not interact significantly with cue type $(F<1)$. Thus, the grouping effects observed in Experiments 1 and 2 were replicated in this experiment, and the size of the effect did not significantly vary between precue and postcue trials.

These findings indicate that the grouping effects observed in Experiments 1 and 2 were not caused primar-

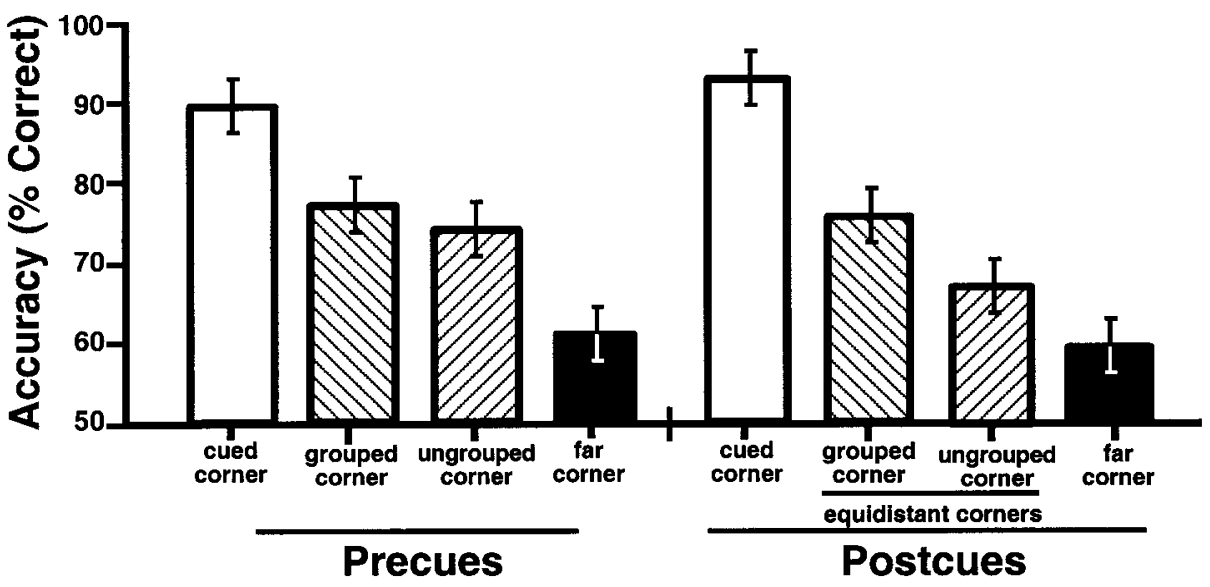

Figure 4. Change detection accuracy in Experiment 3; left, data from the precue condition; right, data from the postcue condition. Error bars represent within-subjects $95 \%$ confidence intervals. 
ily by a spreading of perceptual-level attention within the cued group. Instead, the present results indicate that Gestalt cues directly influence visual working memory storage.

Given that the cue in the postcue condition was presented only $50 \mathrm{msec}$ after the offset of the sample array, is it possible that the cue influenced the perception of the colored squares? There are several factors that make this exceedingly unlikely. First, the colored squares were highly discriminable simple features, and it is unlikely that attending to them could have improved their perceptibility very much. Second, although the delay was only $50 \mathrm{msec}$, this does not mean that the cue had the opportunity to influence perceptual processing $50 \mathrm{msec}$ after the offset of the sample array, because significant time was required to perceive the cue and to shift attention to the cued location. By the time attention was shifted, the sensory input had presumably been absent for 100-200 msec, minimizing opportunities for attention to influence perceptual processing. Third, many previous studies have shown that spatial cues must precede a target to influence the perception of that target (e.g., Eriksen \& Hoffman, 1972; Luck et al., 1996; Lyon, 1990; Nakayama \& Mackeben, 1989). Finally, even if the postcue could have had some influence on perception, its effects should have been significantly smaller than the effects of the precue, which had a greater opportunity to influence perception. Thus, there is every reason to believe that the grouping effects observed in the present experiments directly reflect the storage of information in working memory, rather than being a side effect of changes in perception.

\section{GENERAL DISCUSSION}

The ability of Gestalt grouping cues to bias the perceptual processing of visual information has been studied since the beginning of the last century (Koffka, 1935; Wertheimer, 1912/1961). These grouping cues were originally conceptualized as information that the visual system uses during perceptual analysis to determine what features in the visual field belong together, providing appropriate inputs to later stages of processing. The findings presented in this study suggest that these cues are also used by the visual system to bias the transfer of perceptual representations into working memory. When the to-be-remembered items were grouped according to Gestalt cues, we found that accuracy in the detection of changes was more similar for items in the same group than for items in different groups. Items that were grouped together appeared to have been stored together in visual working memory. Thus, bottom-up information from the visual input can influence the transfer of perceptual information into working memory. This is sensible, because when one part of an object is stored in working memory, it will often be useful for other parts of the object to be stored as well. Presumably, top-down factors interact with these bottom-up factors, allowing the flexible storage of parts or wholes, depending on task demands.
Many previous studies have demonstrated that bottomup information about perceptual organization can influence the allocation of attention (e.g., Driver, McLeod, \& Dienes, 1992; Duncan, 1984; Egly et al., 1994; Moore, Yantis, \& Vaughan, 1998; Vecera \& Farah, 1994). Many investigators have assumed that these effects reflect the spreading of perceptual processing resources within a perceptual group, but this assumption has received little empirical exploration(Vecera, 2000; Vecera \& Behrmann, 2001). The present results can be interpreted as evidence that object-based attention influences the transfer of perceptual representations into working memory. This is also consistent with a recent study by Awh, Dhaliwal, Christensen, and Matsukura (2001), who found that object-based effects occur at a postperceptual stage in Duncan's (1984) overlapping-objects paradigm. However, Awh et al.'s results do not rule out the possibility that object-based attention may also influence perception. For example, Valdes-Sosa, Bobes, Rodriguez, and Pinilla (1998) found that task-irrelevant probes presented on an attended surface yielded enhanced sensoryevoked electrophysiological responses, as compared with probes presented on a spatially overlapped but ignored surface. Thus, some object-based effects may reflect modulations of perception, and others may occur at later stages.

\section{REFERENCES}

Averbach, E., \& Coriel, A. S. (1961). Short-term memory in vision. Bell System Technical Journal, 40, 309-328.

Awh, E., Dhaliwal, H., Christensen, S., \& Matsukura, M. (2001). Evidence for two components of object-based selection. Psychological Science, 12, 329-334.

Baddeley, A. D. (1986). Working memory. Oxford: Oxford University Press, Clarendon Press.

Baddeley, A. D., \& Hitch, G. J. (1974). Working memory. In G. H. Bower (Ed.), The psychology of learning and motivation (Vol. 8, pp. 47-90). New York: Academic Press.

Besner, D., Davies, J., \& Daniels, S. (1981). Reading for meaning: The effects of concurrent articulation. Quarterly Journal of Experimental Psychology, 33A, 415-437.

Brown, J. (1958). Some tests of the decay theory of immediate memory. Quarterly Journal of Experimental Psychology, 10, 12-21.

Carlson-Radvansky, L. A., \& Irwin, D. E. (1995). Memory for structural information across eye movements. Journal of Experimental Psychology: Learning, Memory, \& Cognition, 21, 1441-1458.

Cowan, N. (1998). Visual and auditory working memory capacity: Commentary. Trends in Cognitive Sciences, 2, 77-78.

Dell'Acqua, R., \& Jolicceur, P. (2000). Visual encoding of patterns is subject to dual-task interference. Memory \& Cognition, 28, 184-191.

Driver, J., McLeod, P., \& Dienes, Z (1992). Motion coherence and conjunction search: Implications for guided search theory. Perception \& Psychophysics, 51, 79-85.

DunCAN, J. (1984). Selective attention and the organization of visual information. Journal of Experimental Psychology: General, 113, 501517.

Egly, R, Driver, J., \& RAfal, R. D. (1994). Shifting visual attention between objects and locations: Evidence from normal and parietal lesion subjects. Journal of Experimental Psychology: General, 123, 161-177.

ERIKSEn, C. W., \& Hoffman, J. E. (1972). Temporal and spatial characteristics of selective encoding from visual displays. Perception \& Psychophysics, 12, 201-204.

Irwin, D. E., \& ANDrEws, R. V. (1996). Integration and accumulation of information across saccadic eye movements. In T. Inui \& J. L. Mc- 
Clelland (Eds.), Attention and performance XVI: Information integration in perception and communication (pp. 125-155). Cambridge, MA: MIT Press, Bradford Books.

JiAng, Y., Olson, I. R., \& Chun, M. M. (2000). Organization of visual short-term memory. Journal of Experimental Psychology: Learning, Memory, \& Cognition, 2, 683-702.

KoffKa, K. (1935). Principles of gestalt psychology. New York: Harcourt Brace.

LeE, D., \& Chun, M. M. (2001). What are the units of visual short-term memory, objects or spatial locations? Perception \& Psychophysics, 63, 253-257.

Loftus, G. R., \& Masson, M. E. J. (1994). Using confidence intervals in within-subject designs. Psychonomic Bulletin \& Review, 1, 476-490.

LogIE, R. H. (1995). Visuo-spatial working memory. Hove, U.K.: Erlbaum.

Luck, S. J., Hillyard, S. A., Mouloua, M., \& Hawkins, H. L. (1996). Mechanisms of visual-spatial attention: Resource allocation or uncertainty reduction? Journal of Experimental Psychology: Human Perception \& Performance, 22, 725-737.

Lyon, D. R. (1990). Large and rapid improvement in form discrimination accuracy following a location precue. Acta Psychologica, 73, 6982.

Moore, C. M., Yantis, S., \& Vaughan, B. (1998). Object-based visual selection: Evidence from perceptual completion. Psychological Science, 9, 104-110.

Nakayama, K., \& Mackeben, M. (1989). Sustained and transient components of focal visual attention. Vision Research, 29, 1631-1647.

Neisser, U. (1967). Cognitive psychology. New York: Appleton-CenturyCrofts.

Palmer, J. (1988). Very short-term visual memory for size and shape. Perception \& Psychophysics, 43, 278-286.

Palmer, J. (1990). Attentional limits on the perception and memory of visual information. Journal of Experimental Psychology: Human Perception \& Performance, 16, 332-350.

Palmer, S. E., \& Rock, I. (1994a). On the nature and order of organizational processing: A reply to Peterson. Psychonomic Bulletin \& Review, 1, 515-519.

Palmer, S. E., \& Rock, I. (1994b). Rethinking perceptual organization: The role of uniform connectedness. Psychonomic Bulletin \& Review, 1, 29-55.

Pashler, H. (1988). Familiarity and visual change detection. Perception \& Psychophysics, 44, 369-378.

Peterson, L. R., \& Peterson, M. J. (1959). Short-term retention of individual verbal items. Journal of Experimental Psychology, 58, 193 198.

Phillips, J. L., Shiffrin, R. M., \& AtKinson, R. C. (1967). Effects of list length on short-term memory. Journal of Verbal Learning \& Verbal Behavior, 6, 303-311.

Pollack, I., \& Norman, D. A. (1964). A non-parametric analysis of recognition experiments. Psychonomic Science, 1, 125-126.

Posner, M. I. (1980). Orienting of attention. Quarterly Journal of Experimental Psychology, 32, 3-25.

Potter, M. C. (1976). Short-term conceptual memory for pictures. Journal of Experimental Psychology: Human Learning \& Memory, 2, 509-522.

Rensink, R. A., O'Regan, J. K., \& Clark, J. J. (1997). To see or not to see: The need for attention to perceive changes in scenes. Psychological Science, 8, 368-373.

Schmidt, B. K., Vogel, E. K., Woodman, G. F., \& Luck, S. J. (2002).
Voluntary and automatic attentional control of visual working memory. Perception \& Psychophysics, 64, 754-763.

Simons, D. J. (1996). In sight, out of mind: When object representations fail. Psychological Science, 7, 301-305.

Simons, D. J., \& Levin, D. T. (1997). Change blindness. Trends in Cognitive Sciences, 1, 261-267.

SperLING, G. (1960). The information available in brief visual presentations. Psychological Monographs, 74 (Whole No. 498, pp. 1-29).

Treisman, A. (1988). Features and objects: The Fourteenth Bartlett Memorial Lecture. Quarterly Journal of Experimental Psychology, 40, 201-237.

Valdes-Sosa, M., Bobes, M. A., Rodriguez, V., \& Pinilla, T. (1998). Switching attention without shifting the spotlight object-based attentional modulation of brain potentials. Journal of Cognitive Neuroscience, 10, 137-151.

Vecera, S. P. (2000). Toward a biased competition account of objectbased segregation and attention. Brain \& Mind, 1, 353-384.

Vecera, S. P., \& BehrmanN, M. (2001). Attention and unit formation: A biased competition account of object-based attention. In T. F. Shipley \& P. Kellman (Eds.), From fragments to objects: Segmentation and grouping in vision (pp. 145-180). New York: Elsevier.

Vecera, S. P., Behrmann, M., \& McGoldrick, J. (2000). Selective attention to the parts of an object. Psychonomic Bulletin \& Review, 7, 301-308.

Vecera, S. P., \& Farah, M. J. (1994). Does visual attention select objects or locations? Journal of Experimental Psychology: General, 123, 146-160.

Vecera, S. P., \& O'Reilly, R. C. (1998). Figure-ground organization and object recognition processes: An interactive account. Journal of Experimental Psychology: Human Perception \& Performance, 24, 441-462.

Vogel, E. K., Woodman, G. F., \& Luck, S. J. (2001). Storage of features, conjunctions, and objects in visual working memory. Journal of Experimental Psychology: Human Perception \& Performance, 27, 92-114.

WAlker, P., \& Cuthbert, L. (1998). Remembering visual feature conjunctions: Visual memory for shape-colour associations is objectbased. Visual Cognition, 5, 409-455.

Wertheimer, M. (1950). Gestalt theory. In W. D. Ellis (Ed.), A sourcebook of Gestalt psychology (pp. 1-11). New York: Humanities Press. (Original work published 1924)

WERTHEIMER, M. (1961). Experimental studies on the seeing of motion. In T. Shipley (Ed.), Classics in psychology (pp. 1032-1089). New York: Philosophical Library. (Original published in 1912 as Experimentalle Studien über das Sehen von Bewegung. Zeitschrift für Psychologie, 61, 161-265.)

\section{NOTE}

1. To rule out possible distortions from response bias, all the data were also analyzed using $A^{\prime}$, a nonparametric measure of signal detection sensitivity (Pollack \& Norman, 1964). The analyses of $A^{\prime}$ yielded the same pattern of results as did the analyses of percent correct.

(Manuscript received April 2, 2001; revision accepted for publication February 25, 2002.) 